\title{
Artigo/Article
}

\section{Contaminação bacteriana em concentrados plaquetários: identificação, perfil de sensibilidade aos antimicrobianos e sepse associada à transfusão}

\author{
Bacterial contamination on platelet concentrates: identification, antimicrobial susceptibility \\ profile and transfusion-related sepsis
}

\author{
Rosiéli Martini', Cláudia Barbisan Kempfer', Mônica de Abreu Rodrigues², Fábio Teixeira Kuhn², \\ Fabiane Rigatti ${ }^{1}$, Viviane Ratzlaff ${ }^{3}$, Zanoni Segala ${ }^{3}$ e Rosmari Hörner ${ }^{1,4}$
}

\begin{abstract}
RESUMO
Introdução: Devido à sepse bacteriana associada à transfusão de concentrados plaquetários (CPs) ter sérias consequências clínicas para os pacientes, alguns procedimentos têm sido incorporados na preparação e no controle de qualidade dos componentes sanguíneos para reduzir o risco da contaminação bacteriana. Este artigo descreve a prevalência da contaminação bacteriana dos CPs que foram transfundidos, o espectro bacteriano detectado com seu perfil de sensibilidade aos antimicrobianos e as reações transfusionais nos receptores. Métodos: Um total de 292 CPs (278 randômicos e 14 por aférese), proveniente do Hemocentro do Estado do Rio Grande do Sul (HEMORGS) de Santa Maria foi testado. As quantidades de $100 \mu \mathrm{L}$ e $200 \mu \mathrm{L}$ foram coletadas da porção tubular da bolsa de plaquetas e semeadas utilizando dois tipos de metodologias. Resultados: Em cinco unidades (1,7\%; 5/292) foram isoladas bactérias pela metodologia qualitativa e apenas uma pela quantitativa. Staphylococcus epidermidis foi o microrganismo identificado em todas as amostras. Dois pacientes apresentaram sepse associada à transfusão com desfecho fatal. Conclusões: A contaminação bacteriana pelas transfusões de CPs constitui-se num importante problema de saúde pública devido a sua associação com altas taxas de morbidade e mortalidade. Neste estudo, somente microrganismos gram-positivos foram isolados sendo que nenhuma amostra obtida por aférese apresentou contaminação.
\end{abstract}

Palavras-chaves: Concentrados plaquetários. Contaminação bacteriana. Sepse. Staphylococcus epidermidis.

\begin{abstract}
Introduction: Bacterial sepsis associated with the transfusion of platelet concentrates (PCs) results in serious clinical implications for patients. Given these implications, certain procedures have been integrated into the preparation and quality control of blood components to reduce the risk of bacterial contamination. This article describes the prevalence of bacterial contamination on transfused PCs, the bacterial spectrum detected and their antimicrobial susceptibility profile and transfusion reactions in receptors. Methods: A total of 292 PCs (278 random and 14 per apheresis) from the Blood Center of the State of Rio Grande do Sul (HEMORGS), located in the city of Santa Maria, were tested. Quantities of $100 \mu \mathrm{L}$ and $200 \mu \mathrm{L}$ were collected from platelet bag tubing and seeded using two methodologies. Results: Using the qualitative methodology, bacteria were isolated in five units $(1.7 \% ; 5 / 292)$, while only one was isolated using the quantitative methodology. Staphylococcus epidermidis was the microorganism identified in all samples. Two patients died of transfusion-related sepsis. Conclusions: Bacterial contamination due to PC transfusion is considered a major public health problem due to its association with high rates of morbidity and mortality. In this study only gram-positive microorganisms were isolated and none of the samples obtained by apheresis presented contamination.
\end{abstract}

Key-words: Platelet Concentrate. Bacterial contamination. Sepsis. Staphylococcus epidermidis.

1. Curso de Pós Graduação em Ciências Farmacêuticas, Universidade Federal de Santa Maria, Santa Maria, RS. 2. Iniciação Científica, Laboratório de Bacteriologia, Universidade Federal de Santa Maria, Santa Maria, RS. 3. Hemocentro do Estado do Rio Grande do Sul, Santa Maria, RS. 4. Departamento de Análises Clínicas e Toxicológicas, Universidade Federal de Santa Maria, Santa Maria, RS.

Endereço para correspondência: Profa Rosmari Hörner. Lab Bacteriologia/DACT/UFSM. Prédio 26, sala 1201, Campus da UFSM, 97015-900 Santa Maria, RS.

Telefax: 5555 3220-8751

e-mail: rosmari.ufsm@gmail.com

Recebido para publicação em 02/06/2010

Aceito em 20/08/2010

\section{INTRODUÇÃO}

Embora o risco de infecção viral tenha diminuído consideravelmente nos últimos anos, a contaminação bacteriana de concentrados plaquetários (CPs) é, atualmente, o maior perigo remanescente de infecção em transfusões sanguíneas ${ }^{1,2}$. Mesmo que o número de bactérias presentes na bolsa no momento da coleta seja pequeno, a estocagem destes hemocomponentes a uma temperatura entre 20 $24^{\circ} \mathrm{C}$ por 5-7 dias facilita a replicação bacteriana ${ }^{3,4}$.

Apesar de esta contaminação ser considerada o maior risco de infecção na transfusão de plaquetas, a associação entre as espécies bacterianas responsáveis pela contaminação, a quantidade de Unidades Formadoras de Colônias (UFC) e as reações transfusionais não estão ainda bem caracterizadas ${ }^{5}$.

A transfusão de bolsas de CPs constitui um importante suporte no tratamento de pacientes, especialmente nas unidades de hematologiaoncologia ${ }^{1}$. Por isso há um grande risco na transfusão de produtos sanguíneos contaminados, uma vez que a maioria dos receptores são pacientes imunossuprimidos, mais susceptíveis ao desenvolvimento de complicações clínicas agudas o u retardadas ${ }^{6,7}$.

Microrganismos gram-positivos, principalmente do gênero Staphylococcus são os responsáveis pela maioria dos casos de contaminação dos CPs. A triagem realizada nos serviços de hemoterapia inclui duas etapas: um questionário que analisa as condições de saúde relatadas pelo doador e a realização do controle de qualidade das bolsas. Porém, nem sempre essas etapas poderão identificar a fonte e a presença bacteriana ${ }^{8,9}$. A doação de sangue deve ser em condições assépticas, mediante uma só punção venosa e sistema de coleta fechado e estéril ${ }^{10}$. No Hemocentro do Estado do Rio Grande do Sul (HEMORGS), a higiene do local da punção é realizada primeiramente com algodão embebido com digluconato de clorexidina seguido de álcool $70 \%$. 
No Brasil, atualmente, está em vigor a Resolução da Diretoria Colegiada (RDC) $n^{\circ} 153$, de 14 de junho de $2004^{10}$ do Ministério da Saúde, a qual regulamenta o processo de doação de sangue, de hemocomponentes e de hemoderivados. Considerando que todo o processo desde a coleta, processamento e transfusão de sangue deve ser efetuado com altíssimo controle de qualidade, evitando a propagação de patologias e afastando qualquer tipo de contaminação, esta RDC define que $1 \%$ da produção mensal ou 10 unidades por mês, independente da quantidade produzida, sejam submetidos à cultura para detecção de bactérias ${ }^{10}$.

Os objetivos deste estudo foram determinar a prevalência da contaminação microbiológica nos CPs randômicos e por aférese, a identificação bacteriana e o perfil de sensibilidade aos antimicrobianos de 292 amostras, obtidas no HEMORGS de Santa Maria, Rio Grande do Sul (RS).

\section{MÉTODOS}

Foram analisadas 292 amostras de CPs: 278 obtidos pela centrifugação do sangue total (plaquetas randômicas) e 14 pelo método de aférese (plaquetaférese), coletadas no HEMORGS no período de 2009/2010. O estudo constituiu-se de duas etapas: hemovigilância ativa (prospectiva) e passiva (retrospectiva). As culturas foram realizadas a partir da porção tubular das bolsas de plaquetas, correspondente a um tamanho aproximado de $10 \mathrm{~cm}$, da qual foram retiradas alíquotas equivalentes a um volume médio de $100 \mu \mathrm{L}$ e de $200 \mu \mathrm{L}$ de CPs. Cabe relatar que o fragmento usado neste estudo correspondeu à parte não utilizada pelo HEMORGS. Após a coleta, as amostras foram encaminhadas para o Laboratório de Bacteriologia do Departamento de Análises Clínicas e Toxicológicas (DACT) do Centro de Ciências da Saúde (CCS), onde se realizou esta investigação. Os CPs foram semeados em Cabine de Segurança Biológica II, exaustão total, com prévia desinfecção da porção tubular da bolsa de plaquetas com álcool $70 \%$, por aproximadamente $1 \mathrm{~min}$.

\section{Hemovigilância ativa}

Culturas quantitativas ${ }^{11,12}$ e qualitativas ${ }^{11,13}$ foram realizadas de acordo com a metodologia relatada na literatura, com algumas modificações.

Semeadura em placa de ágar sangue (AS) de carneiro, com contagem (quantitativa)

Dos CPs coletados da porção tubular da bolsa de plaquetas, $100 \mu \mathrm{L}$ foram semeados em AS e incubados a $35^{\circ} \mathrm{C}$ $+/-2^{\circ} \mathrm{C}$ em atmosfera de microaerofilia, por $24-48 \mathrm{~h}$. Posteriormente foi efetuada a análise das placas e a contagem das UFC por mL de CPs. Amostras que apresentaram crescimento bacteriano, independente do número de colônias desenvolvidas, foram consideradas positivas (utilizou-se o fator de multiplicação 10). $\mathrm{Na}$ sequência, foi efetuada a identificação fenotípica e os testes de sensibilidade aos antimicrobianos (TSA) utilizando metodologia convencional ${ }^{14} \mathrm{e}$ automação (MicroScan ${ }^{\circledR}-$ Siemens).

\section{Semeadura em caldo Mueller Hinton (qualitativa)}

Aproximadamente $200 \mu \mathrm{L}$ dos CPs da porção tubular da bolsa de plaquetas foram semeados em $2 \mathrm{~mL}$ de caldo Mueller Hinton e incubados por 5 dias a $35^{\circ} \mathrm{C}+/-2^{\circ} \mathrm{C}$, ar ambiente. Após este período, aproximadamente $10 \mu \mathrm{L}$ do caldo contendo a amostra foram repicados em AS e seguidos os mesmos procedimentos de identificação e TSA. As amostras que em $48 \mathrm{~h}$ não demonstraram nenhum crescimento bacteriano no AS, foram consideradas negativas. Nas amostras com colônias bacterianas (positivas), procedeu-se novamente o repique do caldo, para exclusão de uma possível contaminação.

\section{Testes de sensibilidade aos antimicrobianos}

Foi efetuado com as cepas isoladas utilizando disco-difusão, e automação, seguindo os procedimentos padrões referidos no Clinical and Laboratorial Standards Institute 2010 (CLSI) ${ }^{15}$. Frente ao antimicrobiano vancomicina foi realizada somente a metodologia de microdiluição em caldo com a determinação da concentração mínima inibitória (CIM).

\section{Hemovigilância passiva}

Foi realizada uma análise retrospectiva ${ }^{11,16}$ através da investigação das reações clínicas reportadas nos pacientes os quais receberam as transfusões dos CPs contaminados. Cabe ressaltar que todos os CPs obtidos no HEMORGS são utilizados no Hospital Universitário de Santa Maria (HUSM).

\section{Ética}

O presente trabalho foi submetido e aprovado pelo Comitê de Ética em Pesquisa (CEP) da Universidade Federal de Santa Maria (UFSM), sob o número 0285.0.243.000-09.

\section{RESULTADOS}

Em 5 (1,7\%) das 292 amostras de CPs cultivadas qualitativamente houve crescimento bacteriano. $\mathrm{Na}$ análise quantitativa, apenas em uma amostra (1/292), houve crescimento de $10^{2} \mathrm{UFC} / \mathrm{mL}$ (cultura número 1).

Todas as 5 amostras estavam contaminadas com a mesma espécie bacteriana: Staphylococcus epidermidis. Através dos testes de sensibilidade aos antimicrobianos utilizando difusão do disco e automação (MicroScan ${ }^{\circledR}$-Siemens), as 5 cepas de S. epidermidis isoladas mostraram-se sensíveis frente a sulfametoxazol-trimetoprima, oxacilina, cefoxitina, linezolida, tetraciclina, vancomicina, rifampicina, daptomicina e tigeciclina, e resistentes a eritromicina, penicilina e clindamicina. O CIM da vancomicina para as amostras 1 e 4 foi de $4 \mu \mathrm{g} / \mathrm{mL}$ e para as amostras 2 , 3 e 5 de $2 \mu \mathrm{g} / \mathrm{mL}$ (sensível).

Os dados da hemovigilância passiva encontram-se na Tabela 1. As bolsas número 2, 4 e 5 foram transfundidas por meio de pool de unidades randômicas para o paciente 1 e a bolsa 1 e 3 para os pacientes 2 e 3 , respectivamente.

TABELA 1 - Dados e perfil clínico dos pacientes receptores das bolsas de plaquetas contaminadas das 292 amostras de CPs obtidas no HEMORGS de Santa Maria, Rio Grande do Sul (RS), no período de $2009 / 2010$.

\begin{tabular}{lccc}
\hline & \multicolumn{3}{c}{ Pacientes } \\
\cline { 2 - 4 } Dados e perfil clínico & 1 & 2 & 3 \\
\hline Idade & 23 anos & 46 anos & 1 mês \\
Número de plaquetas & $8.000 / \mathrm{mL}$ & $93.000 / \mathrm{mL}$ & $55.000 / \mathrm{mL}$ \\
Doença de base & Leucemia Mielóide & Nefropatia diabética & Colestase neonatal \\
Setor hospitalar & Aguda (LMA) & & \\
& Unidade de & Unidade nefrológica & Unidade de terapia \\
Antibioticoterapia & hematologia-oncologia & & intensiva \\
Reação febril & Sim & Não & Sim \\
Cultura Qualitativa & Sim: $39^{\circ} \mathrm{C}$ & Sim: $38^{\circ} \mathrm{C}$ & Sim: $39,8^{\circ} \mathrm{C}$ \\
Cultura Quantitativa & Positiva & Positiva & Positiva \\
Hemocultura & Negativa & Positiva(100 UFC $/ \mathrm{mL})$ & Negativa \\
& Positiva: & Não realizada & Negativa \\
Evolução do paciente & Streptococcus sp. & & Alta hospitalar \\
\hline
\end{tabular}




\section{DIscussão}

A sepse associada à transfusão de plaquetas é reconhecida como a mais comum complicação infecciosa da terapia da transfusão sanguínea, sendo duas vezes mais frequente que a transmissão viral associada à transfusão ${ }^{11}$.

Vários estudos já foram realizados empregando metodologias de cultura convencional e automatizada para detectar a contaminação bacteriana em CPs obtidos por aférese e randomicamente ${ }^{13,17,18}$. Todos os CPs contaminados do nosso estudo foram obtidos randomicamente. Porém, no estudo de Hsueh cols ${ }^{19} 1,2 \%$ dos CPs contaminados foram obtidos por aférese e somente $0,3 \%$ randomicamente.

A prevalência da contaminação bacteriana em plaquetas obtidas por um único doador através de aférese (transfundidas isoladamente) e as plaquetas randômicas (obtidas pelo sangue total - 5 a 7 unidades transfundidas em forma de pool) nos EUA, varia de 1:2.000 - 1:3.000, equivalendo a $0,05 \%-0,03 \%$ de contaminação ${ }^{11,20}$.

Recentemente, Walther-Wenke cols ${ }^{18}$ encontraram um valor de 0,3\% de culturas contaminadas de CPs, (169 de 52.243 amostras analisadas), sendo que, em 45 (26,6\%) foram identificados Staphylococcus coagulase negativo (SCN). Hsueh cols ${ }^{19}$ detectaram 0,34\% ( 8 positivas em 2.338 amostras) de contaminação bacteriana em CPs com $75 \%$ ( 6 das 8 contaminações) de S. epidermidis.

Num estudo realizado em um hospital universitário em Goiânia, Brasil, Cunha cols ${ }^{17}$ detectaram uma contaminação bacteriana de $0,4 \%$ de CPs contaminadas ( 8 de 2.000 amostras investigadas), sendo bactérias gram-positivas as responsáveis por $38 \%$ das contaminações.

Yomtovian $\mathrm{cols}^{11}$ em seu estudo realizado em um hospital universitário durante 13 anos (1991 a 2004), empregando diferentes métodos de vigilância para a detecção de contaminação bacteriana em plaquetas, obtiveram um percentual de 0,018\% ( 0,02\%) de CPs contaminados (38/216.283), sendo que em $71 \%(27 / 38)$ das amostras SCN foi o microrganismo isolado.

Cunningham e Cash ${ }^{13}$ detectaram em seu estudo uma taxa de $6,3 \%$ de contaminação bacteriana em CPs, ( 63 positivas de um total de 1.000 amostras), sendo o S. epidermidis responsável por $83 \%$ (52/63) das contaminações.

Os contaminantes encontrados nos CPs são predominantemente bactérias gram-positivas, principalmente Staphylococcus spp o qual faz parte da flora residente da pele $\mathrm{e}^{11,13,18}$. Como a maioria dos contaminantes prevalentes é oriunda da pele, há a necessidade de executar uma desinfecção que seja comprovadamente eficaz no local da punção. A esterilidade dos componentes deverá ser mantida durante o processamento empregando-se métodos assépticos, equipamentos e soluções estéreis e livres de pirogênios, como também a transferência de componente de uma bolsa-satélite para outra deverá realizar-se em circuito fechado ${ }^{10}$.

A septicemia é uma complicação que pode ocorrer após a transfusão de plaquetas com contaminação bacteriana. Há vários casos relatados associando sepse após infusão plaquetáriaa ${ }^{1,18,19,21-24}$. Uma reação transfusional é caracterizada através de sinais e sintomas tais como: febre (com aumento de temperatura de 1 a $2^{\circ} \mathrm{C}$ ), calafrios, tremores, hipotensão, ruborização, náusea, vômitos e choque ${ }^{25}$. Porém, nos pacientes que recebem por transfusão CPs contaminados, esta sintomatologia clínica pode passar facilmente despercebida caso não seja diagnosticada como uma reação transfusional transmitida pelo CP contaminado ${ }^{19}$. Isto porque é complexo diferenciar os sintomas mencionados, devido à sua semelhança com os efeitos adversos dos medicamentos em uso pelos pacientes ou até mesmo por representarem um efeito esperado da antibioticoterapia ${ }^{19}$. Complementarmente, o isolamento de determinados gêneros de microrganismos em um exame cultural de CPs deixa dúvidas na etiologia da sepse ${ }^{19}$.

Comparando as reações transfusionais deste estudo com as de outros grupos de pesquisa, os resultados foram similares ${ }^{1,18,19,21-24}$. Em 1992, Muder cols ${ }^{21}$ descreveram uma reação séptica após infusão plaquetária que estava contaminada por S. epidermidis em um homem de 66 anos que apresentou os sintomas específicos de uma reação transfusional, relatados anteriormente ${ }^{25}$. A cultura do sedimento do pool de plaquetas revelou uma contagem de $10^{5} \mathrm{UFC} / \mathrm{mL}$. Hsueh cols ${ }^{19}$, em 2009, também publicaram em seu estudo uma reação transfusional ocasionada pelo mesmo microrganismo, sem citar ou ter efetuada a quantificação das $\mathrm{UFC} / \mathrm{mL}$.

Em nosso estudo, o paciente 1 (sexo masculino, 23 anos, portador de leucemia mielóide aguda - LMA), conforme mostra a Tabela 1, fazia uso dos antibióticos cefepime, vancomicina e meropenem quando recebeu a primeira bolsa contaminada (bolsa número 2); contudo, não apresentou febre. Depois de 4 dias, sua hemocultura resultou positiva para Streptococcus sp. No $7^{\circ}$ dia, continuava a apresentar plaquetopenia devido a sua condição imunossuprimida. Novamente, em forma de pool, plaquetas foram transfundidas contendo duas unidades de bolsas contaminadas. No $8^{\circ}$ dia, ele apresentou estado febril persistente $\left(38-39^{\circ} \mathrm{C}\right)$ indo a óbito por infecção do trato respiratório inferior e choque séptico.

O paciente 2 (sexo masculino, 46 anos, transplantado de rim) não fazia uso de antimicrobianos no dia da infusão da bolsa de plaquetas contaminada (bolsa número 1 ). No dia seguinte apresentou-se febril $\left(38^{\circ} \mathrm{C}\right)$ e, uma semana depois, submeteu-se a procedimento cirúrgico com prescrição de Clavulin ${ }^{\circledR} 500 \mathrm{mg}$ como tratamento profilático. Porém, devido a falta deste antibiótico na farmácia hospitalar, o paciente fez uso do cefadroxil 500mg. Dois dias depois teve alta.

$\mathrm{O} 3^{\circ}$ paciente tratou-se de um recém-nascido com um mês de vida e colestase neonatal, ao qual eram administrados cefotaxima, vancomicina, amicacina e meropenem. Ele recebeu por transfusão uma das bolsas de plaquetas contaminadas (bolsa 3). Posteriormente apresentou febre $\left(39,8^{\circ} \mathrm{C}\right)$. Foi coletado sangue para hemocultura no dia posterior à transfusão resultando numa hemocultura negativa. O óbito foi registrado no mesmo dia da coleta da hemocultura por choque séptico e extrema colestase.

A transfusão de plaquetas continua sendo imprescindível nos casos de trombocitopenia, cirurgias, acidentes com grande perda sanguínea e no tratamento de pacientes leucêmicos os quais apresentam períodos prolongados de plaquetopenia. Ainda que existam riscos associados, a transfusão de CPs permanece sendo o melhor tratamento frente a estas situações. Portanto, é necessário o aprimoramento das medidas a fim de prevenir, diagnosticar e reduzir a contaminação bacteriana e suas reações transfusionais associadas.

As metodologias convencionais existentes para a detecção da contaminação bacteriana em CPs têm limitações na sensibilidade e especificidade. Neste estudo, a origem das 5 cepas provavelmente foi a pele, por isso, torna-se necessário uma adequada desinfecção das mãos e da pele dos doadores, condições ideais de armazenamento e triagem em 100\% das amostras de CPs obtidas pelos Bancos de Sangue. 
Atualmente, a prevalência da contaminação bacteriana em CPs não se encontra bem caracterizada, possivelmente subestimada. Como é complexa a eliminação da contaminação das bactérias provenientes da pele nos hemocomponentes, é essencial reconhecer os sintomas clínicos iniciais associados com sepse transfusional para a instituição imediata do tratamento adequado.

\section{AGRADECIMENTOS}

Os autores agradecem à equipe de coordenação e controle de qualidade do Hemocentro do Estado do Rio Grande do Sul, Santa Maria, RS.

\section{CONFLITO DE INTERESSE}

Os autores declaram não haver nenhum tipo de conflito de interesse no desenvolvimento do estudo.

\section{SUPORTE FINANCEIRO}

Programa de Pós-Graduação em Ciências Farmacêuticas da Universidade Federal de Santa Maria.

\section{REFERÊNCIAS}

1. Niu MT, Knippen M, Simmons L, Holness LG. Transfusion-transmitted Klebsiella pneumoniae Fatalities 1995 to 2004. Transfus Med Rev 2006; 20:149-157.

2. Palavecino EL, Yomtovian RA, Jacobs MR. Bacterial contamination of platelets. Transfus Apher Sci 2010; 42:71-82.

3. Simon TL, Dzik WH, Snyder EL, Stowel CP, Stauss RG. Rossi's Principles of Transfusion Medicine. $3^{\text {rd }}$ ed. Philadelphia: Lippincott Williams and Wilkins; 2002

4. McDonald CP, Roy A, Mahajan P, Smith R, Charlett A, Barbara JA. Relative values of the interventions of diversion and improved donor-arm disinfection to reduce the bacterial risk from blood transfusion. Vox Sang 2004; 86:178-182.

5. Jacobs MR, Good CE, Lazarus HM, Yomtovian RA. Relationship between Bacterial Load, Species Virulence, and Transfusion Reaction with Transfusion of Bacterially Contaminated Platelets. Clin Infect Dis 2008; 46:1214-1220.

6. Clawson CC, White JG. Platelet interaction with bacteria. I. Reaction phases and effects of inhibitors. Am J Pathol 1971; 65:367-380.

7. University Health System Consortium. University Health Consortium technology assessment. Platelet transfusion guidelines, 1998. Disponível em http://www.uhc.edu.

8. Burns $\mathrm{KH}$, Werch JB. Bacterial contamination of platelet units: a case report and literature survey with review of upcoming American Association of Blood Banks requirements. Arch Pathol Lab Med 2004; 128:279-281.

9. Sazama, K. Bacteria in blood for transfusion. A review. Pathol Lab Med 1994; 18:350-365

10. Ministério da Saúde. Agência Nacional de Vigilância Sanitária (ANVISA). Resolução 153 de 13 de junho de 2004. Determina o Regulamento Técnico para os procedimentos hemoterápicos, incluindo a coleta, o processamento, a testagem, o armazenamento, o transporte, o controle de qualidade e o uso humano de sangue, e seus componentes, obtidos do sangue venoso, do cordão umbilical, da placenta e da medula óssea. Diário Oficial da União, Brasília, DF, 24 de Junho; Seção 1, 2004.p. 68

11. Yomtovian RA, Palavecino EL, Dysktra AH, Downes KA, Morrissey AM Bajaksouzian S, et al. Evolution of surveillance methods for detection of bacterial contamination of platelets in a university hospital, 1991 through 2004. Transfusion 2006; 46:719-730.
12. Guerin GD, Burter LP. Avaliação de Concentrados Plaquetários produzidos pelo serviço de Hemoterapia de Hospital de Santo Ângelo: implantação de um sistema de controle de qualidade. Rev Bras Anal Clin 2006; 38:287-292.

13. Cunningham $M$, Cash JD. Bacterial contamination of platelet concentrates stored at $20^{\circ}$ C. J Clin Pathol 1973; 26:401-404.

14. Koneman EW, Stephen AD, Janda WM, Schreckenberger PC, Winn WC Diagnóstico Microbiológico. Texto e Atlas Colorido. 6ª ed. Rio de Janeiro: Guanabara-Koogan; 2008.

15. Clinical and Laboratory Standards Institute (CLSI). Performance standard for antimicrobial susceptibility testing. Document M100-S20. CLSI, Wayne, PA, 2010

16. Roth VR, Kuehnert MJ, Haley NR, Gregory KR, Schreiber GB, Arduino MJ, et al Evaluation of a reporting system for bacterial contamination of blood components in the United States. Transfusion 2001; 41:1486-1492.

17. Cunha GS, Leão L, Pimenta F. Bacterial contamination of random-donor platelets in a university hospital in the midwestern region of Brazil. Transfusion 2008; 48:282-285.

18. Walther-Wenke G, Schrezenmeier H, Deitenbeck R, Geis G, Burkhart J Höchsmann B, et al. Screening of platelet concentrates for bacterial contamination: spectrum of bacteria detected, proportion of transfused units, and clinical followup. Ann Hematol 2010; 89:83-91.

19. Hsueh JC, Ho CF, Chang SH, Pan FZ, Chen SC, Shi MD, et al. Blood surveillance and detection on platelet bacterial contamination associated with septic events. Transfus Med 2009; 19:350-356.

20. Kleinman SH, Kamel HT, Harpool DR, Vanderpool SK, Custer B, Wiltbank TB et al. Two-year experience with aerobic culturing of apheresis and whole bloodderived platelets. Transfusion 2006; 46:1787-1794.

21. Muder RR, Yee YC, Rihs JD, Bunker M. Staphylococcus epidermidis bacteremia from transfusion of contaminated platelets: application of bacterial DNA analysis Transfusion 1992; 32:771-774.

22. Fang CT, Chambers LA, Kennedy JM, Strupp A, Fucci MC, Janas JA, et al. Detection of bacterial contamination in apheresis platelet products: American Red Cross experience, 2004. Transfusion 2005; 45:1832-1835.

23. Chang AH, Kirsch CM, Mobashery N, Johnson N, Levitt LJ. Streptococcus bovis Septic Shock Due to Contaminated Transfused Platelets. Am J Hemato 2004; 77:282-286

24. Coutinho H, Galloway A, Ajdukiewicz K, Cleeve V. Platelet contamination causing Staphylococcus aureus septicaemia. J Clin Pathol 2010; 63:262-263.

25. Ministério da Saúde. Agência Nacional de Vigilância Sanitária (ANVISA) Hemovigilância: Manual técnico para investigação das reações transfusionais imediatas e tardias não infecciosas, Brasília, DF; 2007. 